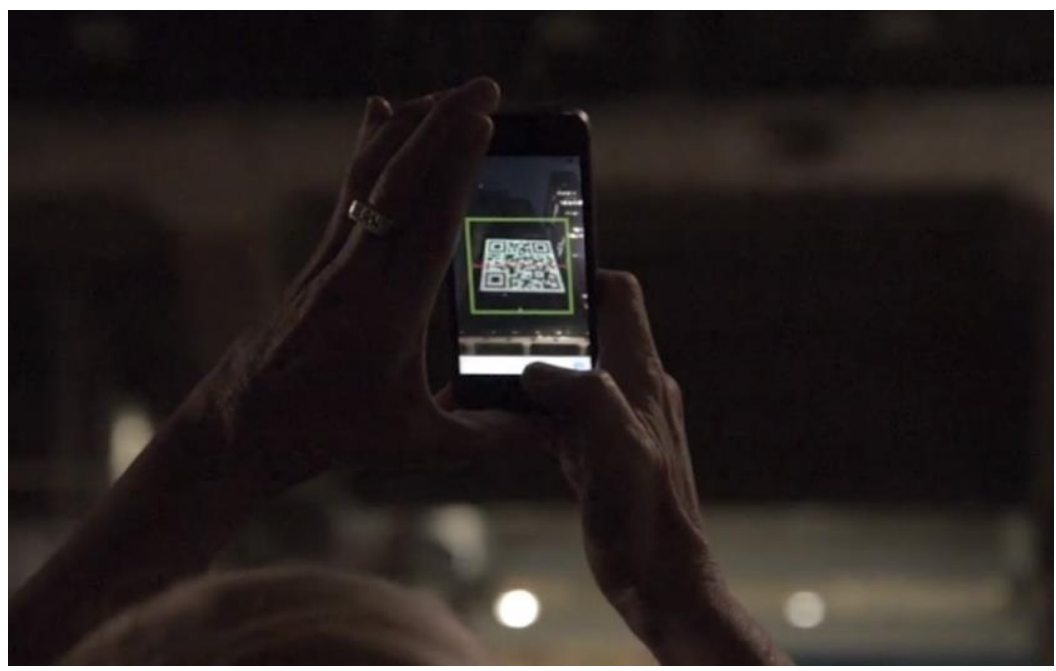

\title{
O exoimaginário urbano
}

The urban exoimaginary

Lucia Santaella ${ }^{1}$

\section{Resumo:}

$\mathrm{Na}$ literatura existente sobre o conceito de imaginário, este é sempre tratado como uma habilidade cognitiva que brota do interior da mente humana. Sem negar essa constatação, o presente artigo visa colocar em discussão que a crescente presença das mídias de registro de imagens, a partir da fotografia, veio gradativamente transformando o imaginário urbano em um exoimaginário, quer dizer, veio colocando o imaginário das cidades para fora da mente, em espetáculos visuais muitas vezes extasiantes. A par disso, com o desenvolvimento dos aparatos de coleta e tratamento de imensos volumes de dados (big data) sobre as cidades, um novo exoimaginário começa a se fazer sentir, o exoimaginário das entranhas do urbano.

Palavras-chave: imaginário. exoimaginário. visualização. big data.

\begin{abstract}
:
In the existing literature on the concept of the imaginary, this is always treated as a cognitive ability that springs from the interior of the human mind. Without denying this notion, the present article aims to put into discussion that the increasing presence of recording media since photography has gradually transformed the urban imaginary into an exoimaginary, that is, images have been putting the imaginary of the cities outside the mind, in visual spectacles often breathtaking. In addition, with the development of the apparatus for collecting and processing large amounts of data (big data) about cities, a new exoimaginary begins to make itself felt, the exoimaginary of the bowels of the urban.
\end{abstract}

Keywords: imaginary. exoimaginary. visualization. big data.

\footnotetext{
1 Professora titular da PUCSP, pesquisadora 1A do CNPq. Recebeu os prêmios Jabuti (2002, 2009 e 2011), o prêmio Sérgio Motta (Líber, 2005) e o prêmio Luiz Beltrão (2010). Publicou 41 livros e mais de 300 artigos. E-mail: lbraga@ @ucsp.br. Orcid: https:// orcid.org/0000-0002-0681-6073
} 


\section{Imaginário e exoimaginário}

O termo imaginário é uma generalização do termo imaginação que, por sua vez, deriva de imagem. São muitas as possibilidades de imagem: mentais, perceptivas, sonoras, visualmente representadas etc. Mais comumente, elas são divididas em dois grandes domínios. O primeiro é o domínio das imagens como representações visuais: desenhos, pinturas, gravuras, fotografias, imagens cinematográficas, televisivas, vídeo, holo e infográficas, animações etc. e todos os seus hibridismos atuais. Imagens, nesse sentido, são objetos materiais, signos produzidos pelo ser humano que se apresentam visualmente. O segundo é o domínio das imagens na nossa mente. Neste domínio, imagens aparecem como visões, fantasias, imaginações, sonhos, esquemas, modelos. Ambos os domínios se entrecruzam. Muitas representações visuais são geradas de imagens na mente daqueles que as produziram. De outro lado, pode-se dizer, que, de alguma forma, as imagens mentais sempre mantêm algum vínculo forte ou fraco com as imagens perceptivas e, especialmente, com as imagens visualmente representadas.

Embora tenha uma ligação com a palavra imagem, o termo imaginário está sempre mais atado ao segundo domínio das imagens, ou seja, ao domínio das imagens mentais. É assim que o conceito de imaginário aparece nas teorias dos autores que mais se notabilizaram sobre o assunto. Sem nenhuma intenção de exaurir o tema, na filosofia de Sartre, por exemplo, em seu conhecido trabalho sobre o imaginário ([1940] 1978), imagem não é exterioridade. Ao contrário, ela corresponde ao ato intencional da consciência. Nas suas palavras, "um trabalho sobre a imagem deve se constituir como uma eidética da imagem, isto é, fixar e descrever a essência dessa estrutura psicológica tal como aparece à intuição" (ibid., 1978, p. 99).

$\mathrm{Na}$ celebrada obra Estruturas antropológicas do imaginário, Gilbert Durand (2002) também privilegia o imaginário como uma das faculdades mentais do ser humano. Para ele, todo pensamento repousa em imagens gerais, os arquétipos, que funcionam como determinações inconscientes do pensamento. Para explicar o simbolismo imaginário, o autor estabelece os núcleos organizadores dos temas arquetipais, uma arquetipologia geral que contrapõe o luxuriante enxame de imagens mentais à lentidão dos processos perceptivos. Nesses enxames dominam a mitologia, a magia, a alquimia e a analogia.

Outro autor que se notabilizou pela construção de uma teoria do imaginário social, no campo da sociologia, foi Cornelius Castoriadis (1975). Para ele, o imaginário é a chave para se pensar os fenômenos coletivos. As sociedades se caracterizam como 
um conjunto de significações sociais imaginárias que se corporificam em instituições nas quais essas significações ganham vida externa.

Como se pode ver, existe uma tendência marcada de se considerar o imaginário como uma faculdade que provém do interior do espírito humano. Isso se constitui em um ponto em comum, não obstante as diferenças teóricas entre os autores. O mesmo se repete em Bachelard e, até certo ponto, em Freud e Lacan, nos quais as fantasias e as ilusões imaginárias ocupam lugar de destaque. Para ficarmos por aqui na menção a autores notáveis, sem negar ou colocar em discussão a natureza da imaginação como uma faculdade que brota das potencialidades mentais do ser humano, a proposta que pretendo defender neste texto, especialmente naquilo que diz respeito ao imaginário arquitetônico e urbano, é que, desde a invenção da fotografia e, cada vez mais crescentemente, o imaginário urbano foi se transformando em um exoimaginário, ou seja, em uma imaginação externalizada, posta para fora. Com a evolução e sofisticação técnica dos meios de registros imagéticos e, especialmente, com o advento do computador como mídia das mídias ou metamídia, essa evolução encontra-se hoje no ponto em que o exoimaginário atinge o nível da visualização do invisível.

\section{A fotografia e o nascimento das metrópoles}

Em meados do século XIX, as transformações urbanas de cidades como Paris e Londres foram modelos de grandes transformações propiciadas pela revolução industrial. Como o fluxo do capital ia se concentrando cada vez mais nos centros urbanos, camponeses e artesãos foram forçados a abandonar suas terras e a fechar seus estabelecimentos. Para permitir a comunicação entre os homens, especialmente dos homens que estavam no comando dos negócios e de sua administração, junto com a fotografia surgiram o telégrafo, o telefone e a consolidação das redes de opinião, os jornais, com notícias rápidas e imediatas. Criava-se, assim, um novo ambiente, o das metrópoles que cresciam no ritmo das novidades. Nas construções arquitetônicas, nos traçados urbanísticos das ruas, nos grandes magazines, nas galerias, nos cassinos, nas exposições, nos museus de cera, e principalmente na moda, a febril imaginação moderna ia se forjando.

O espaço urbano constituía-se na proximidade física quase promíscua de corpos que se esbarravam em espaços exíguos de calçadas tumultuosas, conforme foi pioneiramente descrito por Edgar Allan Poe, em seu conto "O homem na multidão", que 
forte influência exerceu sobre Baudelaire, para ser, depois, brilhantemente tematizado por Walter Benjamin (1989, p. 9-150).

Foi na fotografia e, logo depois, no cinema que os modernos encontraram o que lhes era mais contemporâneo: a velocidade da reprodução e substituição incessante de imagens, pois essas imagens faziam parte de uma cultura organizada sob o signo do choque, de indivíduos que se acostumaram com os desencontros da metrópole. As imagens funcionavam, assim, como espécies de anúncios e síntese das construções de seu tempo especialmente porque podiam ser reproduzidas em toda parte, jornais, revistas, panfletos, vitrines, letreiros e esquinas das cidades (ver Santaella, 2004, p. 2431). Sendo contemporâneos, o surgimento da fotografia e a emergência das metrópoles deram início, daí para frente, a um enamoramento mútuo e a uma aliança que se tornariam indissolúveis: as metrópoles e seus registros fotográficos e cinematográficos. Brotou, com isso, o crescente processo do exoimaginário das cidades.

\section{$O$ agigantamento das metrópoles}

No raio de um século, as metrópoles foram se transformando em megalópoles pari passu ao aumento da sofisticação tecnológica dos aparelhos de foto, cine e vídeográficos. Essa sofisticação intensificou-se com o advento dos equipamentos digitais de captação das imagens e da possibilidade de manipulação computacional das mesmas. Arquiteturas-espetáculo de tirar o fôlego redesenham edifícios que se perfilam no horizonte e atingem altitudes de fazer inveja às mais soberbas montanhas. Sistemas viários e sistemas de iluminação crescem em complexidade nesta era arquimoderna do capitalismo e tudo isso se corporifica em vastos planos de imagens que levam o exoimaginário urbano ao paroxismo, atingindo o que, por enquanto, podemos chamar de ápice de seu potencial.

Entretanto, a inquietante aceleração do crescimento demográfico tem provocado não apenas a expansão contínua das megalópoles quanto tem também levado ao aparecimento de novas metrópoles em um ritmo de crescimento desconcertante. Em razão disso, estão surgindo megacidades que priorizam o investimento na sustentabilidade. Esta surge da necessidade de fazer frente ao conjunto de problemas relativos à qualidade da vida urbana, tais como alterações climáticas, esgotamento de energia e de água, consumo desenfreado, violência e desigualdade social, transporte público escasso etc. Trata-se, portanto, de uma questão que incorpora as dimensões econômica, social, cultural e, sobretudo, política (ver Sampaio, 2009). 
A necessidade e busca pela sustentabilidade tem levado também ao exoimaginário das utopias em imagens que projetam a presença de oásis paradisíacos, longe das agitações barulhentas, agora nas alturas, miragens celestiais, acima das megalópoles agitadas e poluídas.

\section{Mobilidades arquifaceadas}

Enquanto isso, no chão das cidades, as populações hoje se movimentam nos interstícios da mobilidade física e da mobilidade informacional que, geolocalizada, desenha mapas dinâmicos dentro dos territórios em tempos e espaços coincidentes. Nem mesmo vinte anos haviam transcorrido desde o advento da cultura comunicacional planetária do computador, na primeira metade dos anos 1990, quando emergiu a era da mobilidade (Santaella, 2007). Esta provocou grandes transformações no conceito de espaço digital ou ciberespaço, na medida em que o informacional se funde com o espaço físico no ato mesmo em que se dão as conexões. São múltiplos os processos de mobilidade que aí se interconectam.

Uma vez que as sobreposições, cruzamentos, intersecções entre o físico e o informacional são inextricáveis, parece caber com justeza o termo hipermobilidade para caracterizá-los, ou melhor, arquimobilidade arquifaceada, pode-se dizer, para fazer jus ao tema da exposição Arquinterface. A cidade expandida pelas redes, com curadoria de Giselle Beiguelman e Galeria Digital do Sesi/SP (13/nov-13/dez, 2015). “Arqui”, de fato, pois à mobilidade física do cosmopolitismo crescente foi acrescida a mobilidade virtual das redes. Com os aparelhos móveis, ambas as mobilidades se entrelaçaram, interconectaram-se, tornando-se mais agudas pelas ações de uma sobre a outra (ibid, p. 186-187). E atualmente com sistemas como o Waze, o que se tem é a mobilidade teleguiada ao vivo.

Entretanto, a complexidade dos processos não para aí, pois com a imensa potencialização dos meios de registro dos fluxos informacionais, com o aumento exponencial dos dados que podem ser coletados e dos meios correspondentes de processamento que vem sendo chamado de big data, é o exoimaginário urbano que agora vem passando por mudanças inéditas. 


\section{Cidades inteligentes \& big data}

Cidades inteligentes e big data constituem-se na dupla com aparecimento mais frequente nos temas que se encontram atualmente na crista das discussões e mesmo das práticas. Traduzindo-se literalmente big data quer dizer grandes dados, o grande aí significando muita quantidade com potencial para dar um salto rumo à mudança qualitativa. Uma definição mais acurada de big data nos é dada por Boyd e Crawford (2012, p. 663), quando o caracterizam como um fenômeno cultural, tecnológico e acadêmico que se refere ao entrecruzamento de:

(a) Tecnologia: maximização do poder computacional e da precisão algorítmica para juntar, analisar, combinar e comparar grandes conjuntos de dados.

(b) Análise: desenho de grandes conjuntos de dados para identificar padrões a fim de responder a demandas econômicas, sociais, técnicas e jurídicas.

(c) Mitologia: a crença difundida de que grandes conjuntos de dados oferecem uma forma mais elevada de inteligência e conhecimento que gera insights previamente impossíveis, envolvidos na aura da verdade, objetividade e precisão.

O tema das cidades inteligentes, por sua vez, começou a surgir nos anos 2000 . A expansão crescente da internet nos espaços domésticos, públicos, corporativos, governamentais e sua correspondente incorporação na necessária infraestrutura material das cidades trouxeram consigo novas denominações para a cidade como cidadeciborgue, cidade digital e cibercidade. As pesquisas pioneiras sobre essa questão, no Brasil (Lemos 2000, 2004, 2006), estavam prenunciando a conversão crescente das cidades em espaços arquifaceados pela mediação dos equipamentos móveis e dos dispositivos de geolocalização ou GPSs (Global Positioning Systems).

Nossas cidades foram ficando cada vez mais inteligentes à medida que capacidades de processamento de informação iam se enraizando e se espalhando por toda a infraestrutura urbana. A ligação da computação ubíqua com as mídias locativas, isto é, geolocalizadas, permite que as cidades sejam não só lidas, mas também escritas, pois qualquer informação que corre pelas redes pode ser acessada e compartilhada de qualquer lugar para qualquer outro lugar, por meio de tecnologias e serviços baseados em localização (SANTAELLA, 2014). 
Evidentemente, o campo de que depende o desenvolvimento das cidades inteligentes é o campo da governança e da administração governamental. Assim, a egovernança e política 2.0 referem-se a serviços ubíquos de governo, engajamento e participação dos cidadãos, envolvendo, por exemplo, serviços e ontologias de informação semântica governamental. Hoje, a maioria dos sistemas é informatizada e a população está cada vez mais conectada a diferentes mídias e nas redes sociais, o que resulta em volumes gigantescos de dados que implicam coleta, armazenamento das informações e integração de muitas fontes e tecnologias. Para isso, o parque tecnológico tem que ser robusto com vistas à identificação e classificação das informações essenciais para a tomada de decisões. Tudo isso se constitui, vale lembrar, em uma verdadeira apoteose da sociedade de controle, tal como foi pensada por Gilles Deleuze (1992, p. 219-226). É nesse ponto que entra o big data como meio para o entendimento e atendimento dos cidadãos e adoção de processos e ações mais eficazes. O monitoramento e avaliação das informações do big data permitem

oferecer novos meios para autoatendimento para facilitar o acesso e diminuir o tempo gasto pelo cidadão para resolver questões diversas, conferindo mais eficiência e transparência aos processos governamentais. Outra possibilidade é identificar as áreas mais carentes por determinados serviços e alocar melhor os recursos, inclusive os humanos (ELIAS, 2013).

As áreas a serem atendidas pelos serviços governamentais incrementados pelo big data são os transportes, a segurança pública, a saúde, inclusive a saúde preventiva, a educação. O que importa idealmente em tudo isso é que os governos encontrem condições para "unificar os sistemas, analisar melhor os dados, cruzar diferentes indicadores em diversos formatos para definir mais assertivamente seus objetivos e estratégias para aperfeiçoar o atendimento aos cidadãos" (ibid.).

Entretanto, o que mais interessa, no que concerne à questão do exoimaginário, diz respeito ao fato de que os resultados dos processamentos do big data são expressos em imagens de visualização. Sempre houve métodos estáticos de representação visual de dados. As tecnologias digitais, entretanto, introduziram os espaços de informação, ou seja, modelos dinâmicos de visualização para a experimentação e pesquisa nos mais variados campos das ciências, estatística, arquitetura, design, arte ou quaisquer combinações entre eles (PAUL, 2003, p. 175). Graças aos softwares, esses modelos são dinâmicos porque seus dados podem ser mapeados em outro domínio semiótico, do tempo para o espaço $2 \mathrm{D}$, da imagem $2 \mathrm{D}$ para a espaço $3 \mathrm{D}$, do som para a imagem $2 \mathrm{D}$ 
etc. Além disso, os modelos podem ser manipulados pelo uso das técnicas de interface: busca, filtro, zoom, múltiplos pontos de vista, sumariar etc.

Ademais, visualizações dinâmicas de fluxos de dados permitem que os usuários naveguem pela informação, experimentando as mudanças que ocorrem no tempo. Nesse contexto, "mapeamento" é um termo utilizado para levantar questões acerca dos territórios que estão sendo rastreados. Diferentemente dos mapas tradicionais, que têm por referente um terreno exterior relativamente estático e que são utilizados para orientar os usuários nos terrenos referidos, o mapeamento de informações digitais está, por natureza, em permanente fluxo, pois ele responde às constantes mudanças que se operam nos dados representados.

Manovich (2002) define visualização como as situações em que dados quantitativos, que, por sua natureza, não são visuais -- por exemplo, os sinais recebidos pelos sensores meteorológicos, o comportamento da bolsa de valores, o conjunto de endereços descrevendo a trajetória de uma mensagem através de uma rede computacional - são transformados em representações visuais. É a visualização dinâmica que "pode transformar um arquivo de dados incompreensíveis em algo mais do que uma fileira sem significado de bits e pedaços de uma série infinita de fragmentos não relacionados".

Quando os sistemas de visualização têm por objeto os dados acerca dos inumeráveis tipos de fluxos dos ambientes urbanos, ou seja, a existência pulsante dos movimentos da cidade viva, trata-se aí de dados invisíveis que a visualização torna visível. É nesse ponto que ao exoimaginário atinge seu ponto mais culminante. À maneira de um sismógrafo, o big data captura as redes capilares da multiplicidade de fluxos urbanos, devolvendo aos nossos olhos imagens dotadas de um sabor estético que chega a ser inebriante.

\section{A arte a contrapelo do exoimaginário mimético}

Todas as formas de externalização do imaginário urbano até aqui discutidas apresentam uma característica comum. Elas mimetizam o visível, quer dizer, por meio de fotos, filmes e vídeos registram as imagens das cidades, criando duplos de territórios, espaços e ambientes urbanos, algumas vezes não visíveis a olho nu e exibindo uma grandiosidade conquistada por meio de equipamentos técnicos sofisticados. Embora possa se pensar diferente, as hipercomplexas imagens de visualização de dados, que tornam visível o invisível, são também miméticas, um tipo de mimese que não se limita 
a imitar a aparência dos ambientes urbanos, mas diagrama as relações internas dos seus fluxos, devolvendo-as à visibilidade. Portanto, nem mesmo as imagens de visualização fogem à regra mimética do exoimaginário urbano.

Existe, no entanto, um campo multifacetado, da atividade humana que, em lugar de duplicar a aparência do urbano, acrescenta à urbis algo que ela jamais poderia ter, caso o espírito criador humano nela não interferisse. Refiro-me aqui à arte urbana e às intervenções urbanas. Suas modalidades são inúmeras, sempre atentas aos entrelaçamentos nas malhas no tecido urbano. "A função da arte é construir imagens da cidade que sejam novas, que passem a fazer parte da própria paisagem urbana" (BRISSAC, 1996, p. 13). Quer dizer, imagens "novas", não miméticas, que transmutam o exoimaginário, reinventando as formas de habitar na redescoberta das cidades. São, portanto, formas de criação que vão a contrapelo do exoimaginário mimético.

O espectro da arte urbana é vasto, desde suas formas mais populares até as interferências que fazem uso das tecnologias mais complexas da atualidade. A forma popular bem conhecida é a do grafite e dos murais, arte das ruas por excelência. Mas as apropriações do espaço público englobam também as estátuas vivas, os malabarismos, os teatros e danças de rua etc. As intervenções artísticas, um dos tipos possíveis de arte urbana, variam nas suas dimensões, desde o uso de adesivos até as grandes instalações. Variam também na sua natureza, desde as encenações críticas de caráter político e ideológico, visando denunciar problemas sociais e ambientais, até os projetos que são realizados por encomenda do poder público. Alguns projetos estão voltados para a reabilitação funcional e simbólica, inclusive pelo acréscimo de novos usos, de territórios ou de edificações, visando integrar a população nesses espaços. As linguagens e técnicas empregadas nas intervenções são também heterogêneas e vão desde ações passageiras a céu aberto, inserções variadas no ambiente urbano até a criação de novas paisagens urbanas antes inexistentes, mesmo que a preço da efemeridade.

A criação de paisagens que expõem o exoimaginário não-mimético de forma mais patente encontra-se nas fotografias hiperdimensionadas, nos festivais de luzes, nos painéis digitais, nos videomappings que intervêm na arquitetura da cidade, transformando ruas e fachadas inteiras de edifícios em espaços expositivos. Ou mais ainda, quando incorporam estrategicamente os minidispositivos inteligentes, os celulares, que os cidadãos têm em mãos, para levá-los a atuar, interagir e participar dos trabalhos, como foi exemplarmente o caso da exposição Arquinterface, realizada nas fachadas de 98 metros de altura do edifício da Fiesp, na Avenida Paulista de SP. 
A marca principal da arte urbana encontra-se, assim, na grande diversidade de suas propostas e implicações. Por seus parentescos com o Dada, o movimento Fluxus, o happening, a performance, os acionistas, a body art e até mesmo com a arte conceitual, as intervenções urbanas ganharam status no circuito das artes, embora muitas vezes fiquem à margem das curadorias dos museus, das galerias ou de qualquer forma tradicional de exposição. Além disso, não são muito claras as fronteiras que podem distinguir as intervenções urbanas das instalações, da land art e especialmente do site specific.

O que perfila a especificidade da arte urbana, em meio aos parentescos, é que se trata de uma arte que particulariza lugares, recriando as paisagens da cidade. Conduz, assim, a uma experiência estética que produz maneiras regeneradas de perceber, habitar e se afeiçoar à cidade. Ao interceptar os olhares, os passos e as expectativas dos habitantes, por meio da surpresa, do humor, da ironia, da inquietação, do estranhamento e do questionamento, essa arte desestabiliza o exoimaginário mimético que tomou conta das formas de representação da cidade e que tornou tudo visível demais. Contra isso, "a arte na cidade contemporânea só pode aludir ao que ali nos escapa, ao que ali não tem lugar” (BRISSAC, 1996, p. 42). Há muito mais encantos secretos no que falta ver, no que se busca ver, do que naquilo que se escancara à visão.

\section{Referências}

BENJAMIN, Walter. Obras escolhidas III. Charles Baudelaire. Um lírico no auge do capitalismo. São Paulo: Brasiliense, 1989.

BOYD, Dana e CRAWFORD, Kate. Critical questions for big data. Information, Communication \& Society, 15:5, 2012, p. 662-679.

BRISSAC, Nelson. Paisagens urbanas. São Paulo: Senac/Marca D’Água/Fapesp, 1996.

CASTORIADIS, Cornelius. La institución imaginaria de la sociedad . Barcelona: Tusquets Editores, 1975.

DELEUZE, Gilles. Post-scriptum sobre as sociedades de controle. Em Conversações, Peter Pál-Pelbart (trad.). Rio de Janeiro: Ed. 34, 1992, p. 219-226.

DURAND, Gilbert. Estruturas imaginárias do imaginário. São Paulo: Martins Fontes, $3^{\mathrm{a}}$. ed., 2002.

ELIAS, Fabio. Big Data é oportunidade para o setor público. Em

http://www.guiadascidadesdigitais.com.br/site/pagina/big-data-oportunidade-para-osetor-pblico, 2013. Acesso: 05/05/2014.

LEMOS, André. Cibercidades. In Janelas do ciberespaço. Comunicação e cultura. André Lemos e Marcos Palacios (orgs.). Porto Alegre, Sulina, 2000. 
Cidade-ciborgue: A cidade na cibercultura. Galáxia, no.8, 2004, p. 129-

148.

Cibercidade. Critical Dictionary of Globalisations. Em

http://www.mondialisations.org/php/public/art.php?id=22897\&lan=PO. 2006. Acesso $11 / 10 / 2011$.

MANOVICH, Lev. The anti-sublime ideal in data art. Disponível em www.manovich.net/DOCS/data_art.doc. 2002. Acesso em 20/01/2010.

PAUL, Christiane. Digital art. New York: Thames \& Hudson, 2003.

SAMPAIO, Danusa Teodoro. Sustentabilidade Urbana: Conceitos e Controvérsias. IV Encontro Nacional e III Encontro Latino-Americano sobre edificações e comunidades sustentáveis. Em

http://www.iau.usp.br/pesquisa/grupos/habis/biblioteca/digital/artigos/sustentabilidade/ Artigo_ELECS2009_Sustentabilidade\%20Urbana_conceitos\%20e\%20controversas_Sa mpaio.pdf. 2009. Acesso: 15/10/2015.

SANTAELLA, Lucia. Navegar no ciberespaço. O perfil cognitivo do leitor imersivo. São Paulo: Paulus, 2004. . Linguagens líquidas na era da mobilidade. São Paulo: Paulus, 2007. Dos não-lugares às cidades sencientes. Revista RUA, no. 20, vol. II, 2014.

SARTRE, J. P. L'imaginaire. Paris: Gallimard, 1940. Tradução para o português: $O$ imaginário. São Paulo: Abril Cultural, 1978.

STAFFORD, Barbara Maria. Good looking: essays on the virtue of images. Cambridge, MA: MIT Press, 1996. 


\section{Para citar essa obra:}

SANTAELLA, Lucia. O exoimaginário urbano. In: RUA [online]. $\mathrm{n}^{\circ}$. 24 . Volume $1-$ p. 05-15 - e-ISSN 2179-9911 - junho/2018. Consultada no Portal Labeurb - Revista do Laboratório de Estudos Urbanos do Núcleo de Desenvolvimento da Criatividade.

http://www.labeurb.unicamp.br/rua/

Capa: Print do Vídeo \#QR-Comms de Giselle Beiguelman. Vídeo disponível em https://vimeo.com/135069087

Laboratório de Estudos Urbanos - LABEURB

Núcleo de Desenvolvimento da Criatividade - NUDECRI

Universidade Estadual de Campinas - UNICAMP

http://www.labeurb.unicamp.br/

Endereço:

LABEURB - LABORATÓRIO DE ESTUDOS URBANOS

UNICAMP/COCEN / NUDECRI

CAIXA POSTAL 6166

Campinas/SP - Brasil

CEP 13083-892

Fone/ Fax: (19) 3521-7900

Contato: http://www.labeurb.unicamp.br/contato 